\title{
Systemic impairment in relation to disease burden in patients with moderate COPD eligible for a lifestyle program. Findings from the INTERCOM trial
}

\author{
Carel $\mathrm{R}$ van Wetering' \\ Floortje E van Nooten ${ }^{2}$ \\ Stijn J M Mol ${ }^{3}$ \\ Martine Hoogendoorn² \\ Maureen P M H Rutten-van \\ Mölken² \\ Annemie M Schols ${ }^{4}$ \\ 'Department of Physiotherapy, \\ Máxima Medical Centre, Veldhoven, \\ The Netherlands; ${ }^{2}$ Institute \\ for Medical Technology Assessment, \\ Erasmus Medical Centre, Rotterdam \\ The Netherlands; ${ }^{3}$ Department \\ of Respiratory Medicine, Máxima \\ Medical Centre, Veldhoven, \\ The Netherlands; ${ }^{4}$ Department \\ of Respiratory Medicine, \\ Maastricht University, Maastricht, \\ The Netherlands
}

Introduction: In contrast with the frequency distribution of chronic obstructive pulmonary disease (COPD) stages in the population, in which the majority of the patients is classified as GOLD 2, much less information is available on the prevalence and implications of systemic manifestations in less severe patients relative to GOLD 3 and 4.

Aim: To characterize local and systemic impairment in relation to disease burden in a group of GOLD 2 COPD patients ( $n=127$, forced expiratory volume in one second (SD): $67(11) \%$ pred) that were eligible for the Interdisciplinary Community-based COPD management (INTERCOM) trial.

Methods: Patients were included for this lifestyle program based on a peak exercise capacity (Wmax) $<70 \%$ of predicted. Metabolic and ventilatory response to incremental cycle ergometry, 6 minute walking distance (6MWD), constant work rate test (CWR), lung function, maximal inspiratory pressure (Pimax), quadriceps force $(\mathrm{QF})$, quadriceps average power $(\mathrm{QP})$ (isokinetic dynamometry), handgrip force (HGF) and body composition were measured. Quality of life (QoL) was assessed by the St. George's Respiratory Questionnaire (SGRQ) and dyspnea by the modified Medical Research Council (MRC) dyspnea scale. Exacerbations and COPD-associated hospital admissions in 12 months prior to the start of the study were recorded. Burden of disease was defined in terms of exercise capacity, QoL, hospitalization, and exacerbation frequency. GOLD 2 patients were compared with reference values and with GOLD 3 patients who were also included in the trial.

Results: HGF (77.7 (18.8) \% pred) and Pimax (67.1 (22.5)\% pred) were impaired in GOLD 2, while QF (93.5 (22.5)\% pred) was only modestly decreased. Depletion of FFM was present in $15 \%$ of weight stable GOLD 2 patients while only $2 \%$ had experienced recent involuntary weight loss. In contrast to Wmax, submaximal exercise capacity, muscle function, and body composition were not significantly different between GOLD 2 and 3 subgroups. Body mass index and fat-free mass index were significantly lower in smokers compared to ex-smokers. In multivariate analysis, QF and diffusing capacity (DLco) were independently associated with Wmax and 6 MWD in GOLD 2 while only 6 MWD was identified as an independent determinant of health-related QoL. HGF was an independent predictor of hospitalization.

Conclusions: This study shows that also in patients with moderate COPD, eligible for a lifestyle program based on a decreased exercise capacity, systemic impairment is an important determinant of disease burden and that smoking affects body composition.

Keywords: COPD, systemic impairment, lifestyle, pulmonary rehabilitation

\section{Introduction}

The burden of chronic obstructive pulmonary disease (COPD) is projected to increase excessively in the next decade (Murray et al 1997). Disability-adjusted life years lost will 
dramatically increase as COPD is expected to move from the 12th rank in 2000 to the 5 th rank in 2020 (Hurd 2000). A major component of disability is an impaired exercise capacity. In severe COPD systemic manifestations such as peripheral skeletal muscle weakness and muscle wasting are important determinants of impaired exercise performance (Gosselink et al 1996; Wouters 2002). Also in severe COPD, the relation between muscle dysfunction and the burden of the disease has been clearly established. Several studies have shown that low body mass index (BMI) and fat free mass (FFM), as marker of muscle mass, are independent predictors of mortality in patients with severe COPD (Gray-Donald et al 1996; Landbo et al 1999; Schols et al 2005). Muscle function has been identified as a determinant of utilization of health care resources (Decramer et al 1997). Muscle wasting and muscle dysfunction are partly reversible by pulmonary rehabilitation (Bourbeau et al 2003; Griffiths et al 2001; Nici et al 2006).

In contrast with the frequency distribution of COPD stages in the population, where most diagnosed patients are staged GOLD 2 (Hoogendoorn et al 2006), little information is available on the prevalence and implications of systemic manifestations in these less severe COPD. It is therefore important to determine, whether the concept of COPD as a systemic disease can be extended to less severe stages of the disease. We hypothesized that in moderate COPD patients with an impaired exercise capacity, muscle wasting and weakness would also be present and would contribute to disease burden. This would provide a rationale for the application of lifestyle programs that encourage the incorporation of exercise training into daily life, provide smoking cessation support, improve dietary intake, provide psychosocial support, and stimulate self-management even in earlier disease stages. To assess the cost-effectiveness of an interdisciplinary community-based COPD management program that includes all the above mentioned elements of a lifestyle program, we started the Interdisciplinary Community-based COPD management (INTERCOM) trial, a randomized controlled trial. Aim of the present study was to characterize local and systemic impairment in the patients that were enrolled in this trial. Furthermore, we aimed to identify factors independently associated with an increased burden of COPD in these patients where burden was defined in terms of impaired exercise capacity, quality of life (QoL), exacerbations, and hospitalizations.

\section{Material and methods}

\section{Patients and setting}

The INTERCOM trial recruited newly detected patients and patients with a history of COPD, medically treated at the department of respiratory medicine of two general hospitals in Eindhoven, the Netherlands. Patients were included when peak exercise capacity (Wmax) during an incremental cycle ergometer test was less than $70 \%$ of predicted normal values (Jones et al 1985). Patients who had prior rehabilitation and patients with serious comorbidity that precluded exercise were excluded. Patients were judged to be clinically stable at inclusion and pharmacotherapy had been optimized. All patients gave written informed consent for participation in the study. Ethical approval was granted by the Medical Ethical Committee of the Máxima Medical Centre.

\section{Baseline assessments}

\section{Lung function}

Forced expiratory volume in one second $\left(\mathrm{FEV}_{1}\right)$ and inspiratory capacity were derived from the flow volume curve with the use of a spirometer (Masterlab, Jaeger, Wurzburg, Germany). Diffusing capacity for carbon monoxide (DLco) was determined with the single breath method (Masterlab) (Quanjer 1993).

\section{Body composition}

Body weight was measured using digital scales (Seca, Vogel Halke, Hamburg, Germany). Height was measured using a wall mounted stadiometer with subjects standing barefoot. BMI was calculated as weight $/$ height $^{2}\left(\mathrm{~kg} / \mathrm{m}^{2}\right)$. FFM was estimated with single-frequency $(50 \mathrm{kHz})$ bioelectrical impedance analysis (Bodystat 1500, Bodystat Ltd. Douglas, Isle of Main, Britain). Resistance was measured with subjects in the supine position. FFM was calculated with the diseasespecific regression equation (Schols et al 1991). Depletion of fat free mass was defined as FFMI $\leq 15$ (female) $/ \leq 16$ (male) $\mathrm{kg} / \mathrm{m}^{2}$. Nutritional depletion was defined as BMI $\leq 21$ and/or FFMI $\leq 15$ (female) $/ \leq 16$ (male) $\mathrm{kg} / \mathrm{m}^{2}$. Involuntary weight loss was defined as weight loss of at least $5 \%$ in one month or at least $10 \%$ in six months prior to admission to the COPD management program while the BMI was at most $25 \mathrm{~kg} / \mathrm{m}^{2}$. Fat mass was expressed as percentage of total body mass.

\section{Respiratory and peripheral muscle function}

Respiratory muscle function was assessed by measuring maximal inspiratory mouth pressure (Pi-max) according to the method of Black and Hyatt (Masterlab; Black et al 1969). The highest value of five technically satisfactory measurements was used for analysis. Pi-max values were recorded as positive values.

Peripheral muscle function was assessed by the handgrip force (HGF) and the isometric and isokinetic quadriceps force. 
Isometric HGF in pounds was measured with a hydraulic hand dynamometer (Yamar Preston). The force was measured three times in each hand. The highest value of the right hand was used in the analyses. Isometric and isokinetic quadriceps function were measured using a Biodex system 3 (New York, NY) dynamometer. Peak torque (QF) in Newton-meters (Nm) was measured at the dominant side, during a maximal isometric knee extension manoeuvre with the hip in $90^{\circ}$ flexion and the knee in $60^{\circ}$ flexion. The highest value of three attempts was used in the analysis. Average power (QP) in Watt (W) was measured during an isokinetic test at a speed of $60^{\circ}\left(\mathrm{QP}-60^{\circ}\right)$ and $180^{\circ} /$ second $\left(\mathrm{QP}-180^{\circ}\right)$ during 5 and 10 contractions respectively from $0^{\circ}$ till $90^{\circ}$ knee flexion.

\section{Exercise capacity}

Exercise capacity was measured using an incremental cycle exercise test, a constant work rate test (CWR) and a 6 minute walking test. The incremental exercise test and the CWR test were performed on an electro magnetically braked cycle ergometer (Corrival 1, Lode, Groningen, The Netherlands. Arterial blood samples were taken at rest and during the last minute from the forearm. Arterial oxygen tension $\left(\mathrm{PaO}_{2}\right)$ and carbon dioxide pressure $\left(\mathrm{PaCO}_{2}\right)$ were analyzed on a blood gas analyzer (ABL 800 flex, Radiometer, Copenhagen, Denmark). Measurements of pulmonary ventilation $\left(\mathrm{V}_{\mathrm{E}}\right)$ and respired fractions of oxygen uptake $\left(\mathrm{VO}_{2}\right)$ and carbon dioxide output $\left(\mathrm{VCO}_{2}\right)$ were obtained breath by breath (Oxycon $\alpha$, Jaeger, Wurzburg, Germany). An individualized ramp protocol was used and the test was ended when the patient was not able to maintain the required pedalling frequency. Peak heart rate (HR) was calculated as 220 - age, and peak ventilatory minute ventilation $(\mathrm{VE})$ was calculated as $\mathrm{FEV}_{1} \times 37.5$.

The CWR test was performed at $50 \%$ of the peak work rate (CWR 50\%) during maximal 10 minutes. Thereafter the test was continued at $70 \%$ of peak work rate (CWR 70\%) until exhaustion occurred. The 6 minutes walking test measured the distance walked during 6 minutes (6 MWD) in a 50-meter corridor in the hospital. The test was performed without encouragement and was repeated two times on nonconsecutive days. The largest distance was used in the analysis.

\section{Dyspnea}

The degree of dyspnea was measured with the modified Medical Research Council (MRC) dyspnea scale (Fletcher et al 1959; Bestall et al 1999).

\section{Health-related QoL}

Disease-specific QoL was assessed with the St. George's Respiratory Questionnaire (SGRQ) (Jones et al 1992). The
SGRQ is a 50-item self-administered questionnaire developed to measure the impact of asthma or COPD on health-related QoL and well-being. Responses can be aggregated into an overall score and three sub scores for 'symptoms', 'activity' and 'impact'.

\section{Exacerbation rate}

An exacerbation was defined as an increase in respiratory symptoms that initiated treatment with oral corticosteroids and/or antibiotics. Exacerbations 12 months prior to the start of the study were taken into account. These exacerbations were self-reported.

\section{Hospital admission rate}

All COPD-related hospital admissions during a timeframe of 12 months before the patient's entry into the trial were retrieved from the electronic hospital records.

\section{Statistical analysis}

Descriptive statistics of demographic and lung function characteristics, exercise performance, body composition, muscle function, dyspnea, QoL, exacerbation, and hospitalization rate at baseline of the INTERCOM trial are provided and where possible compared to reference values to adequately describe the patient population in this trial. Because of limited availability of appropriate reference values, GOLD 2 patients were also compared to the GOLD 3 patients participating in the same trial using either Independent-Samples T-tests, nonparametric Mann-Whitney U-tests or Chi-Square tests. Differences between groups were also tested with multivariate analysis of covariance (ANCOVA) adjusted for gender and smoking status.

In univariate analyses of variance, the association between Wmax, 6MWD, and SGRQ score on the one hand and functional variables on the other hand was assessed using ANCOVA with GOLD stage as a factor. This was followed by stepwise multiple regression analyses with Wmax, 6 MWD, and SGRQ score as dependent variables and all patient characteristics known to be related to these dependent variables in patients with more severe COPD. Differences between GOLD 2 patients with and without exacerbations or hospitalizations were compared with Independent Samples T-test. Logistic regression analyses were performed to conduct univariate and multivariate analyses of the association between COPD-related exacerbations and hospital admissions as dependent variables and patient characteristics previously found to be related to these variables as independent variables. Variables were removed from the 
regression equation when their $\mathrm{p}$ value was greater than 0.10 .

Furthermore the collinearity statistics of the independent variables in terms of tolerance were used to prevent high correlations between the variables in the regression model (Landis et al 1977). SPSS version 12 (SPSS Inc., Chicago, IL) was used for the computations.

\section{Results}

\section{Patient enrolment}

Figure 1 shows the patient enrolment scheme. Data of 180 patients were included in this analysis. Of these 180 patients, 127 (71\%) had GOLD 2 COPD and 53 (29\%) had GOLD 3 COPD.

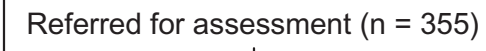

Written informed consent $(n=199)$

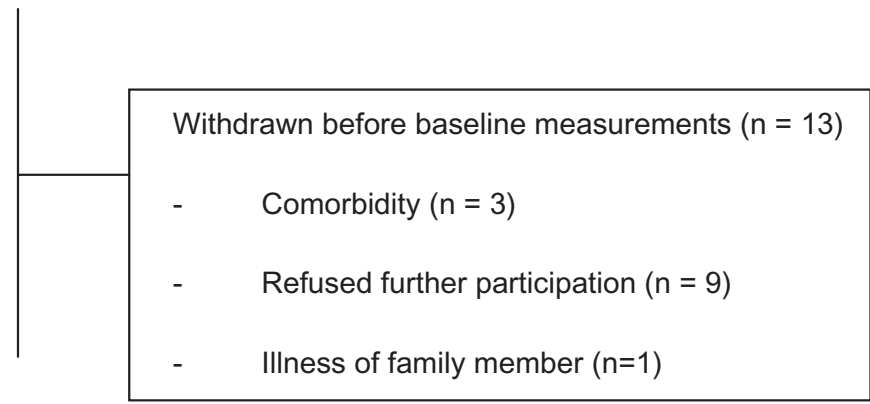

Participants with baseline measurements $(n=186)$

Not GOLD 2-3 $(n=6)$

Figure I Patient enrolment scheme. 


\section{Pulmonary function, health-related QoL, dyspnea, exacerbations, and hospitalization}

Table 1 compares the demographic and lung function characteristics of the GOLD 2 and GOLD 3 patients, as well as the QoL, dyspnea, exacerbation, and hospitalization data. QoL was significantly more impaired in GOLD 3 compared with GOLD 2.

Exacerbation frequency was significantly higher in GOLD 3 patients, but there was no difference between GOLD 2 and GOLD 3 patients in COPD-related hospital admissions.

\section{Exercise performance, muscle function, and body composition}

After adjustment for smoking status and gender, significant differences between patients with GOLD 2 and patients with GOLD 3 were present in Wmax, peak minute ventilation, respiratory quotient (RQ), and carbon dioxide output, $\mathrm{PaO}_{2}$, $\mathrm{PaCO}_{2}$ at peak work rate. Wmax was significantly $(\mathrm{p}<0.001)$

Table I GOLD classification, baseline pulmonary function, healthrelated quality of life, dyspnea score, exacerbation frequency, and hospitalization

\begin{tabular}{|c|c|c|c|c|c|}
\hline & GOLD 2 & & GOLD 3 & & \\
\hline & Mean & SD & Mean & SD & $\mathrm{p}$-value \\
\hline n (\%); & 127 (7I\%) & & $53(29 \%)$ & & \\
\hline $\mathrm{n}$; male $(\%) \ddagger$ & 88 (69 \%) & & 44 (83\%) & & n.s. \\
\hline Age; yr & 67 & \pm 9 & 66 & \pm 8 & n.s. \\
\hline $\begin{array}{l}\text { Current smoker; } \\
\text { n (\%) } \ddagger\end{array}$ & $40(31 \%)$ & & II (2I\%) & & n.s. \\
\hline Never smoker; $\mathrm{n} \ddagger$ & $8(6 \%)$ & & $2(4 \%)$ & & \\
\hline Pack years ${ }^{\wedge}$ & 38 & & 37 & & n.s. \\
\hline FEV, \% pred & 67 & \pm 11 & 43 & \pm 5 & $\mathrm{P}<0.001$ \\
\hline ITGV \% pred & 128 & \pm 27 & 150 & \pm 28 & $\mathrm{P}<0.001$ \\
\hline RV \% pred & 139 & \pm 31 & $17 \mid$ & \pm 38 & $\mathrm{P}<0.001$ \\
\hline DLco \% pred & 72 & \pm 23 & 60 & \pm 18 & $\mathrm{P}<0.001$ \\
\hline SGRQ total & 35.7 & \pm 14.8 & 43.4 & \pm 13.7 & 0.002 \\
\hline SGRQ symptom & 41.8 & \pm 21.1 & 46.3 & \pm 19.6 & n.s. \\
\hline SGRQ activity & 52.7 & \pm 18.6 & 62.4 & \pm 16.1 & 0.001 \\
\hline SGRQ impact & 23.9 & \pm 15.1 & 31.2 & \pm 16.1 & 0.004 \\
\hline $\mathrm{MRC} \sim$ & 2.6 & \pm 2.0 & 2.8 & \pm 2.0 & n.s. \\
\hline VAS dyspnea & 69.4 & \pm 13.9 & 68.5 & \pm 14.8 & n.s. \\
\hline Exacerbations ^ & I & 1.6 & 1.3 & 1.2 & 0.011 \\
\hline Hospital admission ${ }^{\wedge}$ & 0.14 & $0.4 I$ & 0.17 & 0.43 & n.s. \\
\hline
\end{tabular}

Notes: Data are presented as mean \pm SD unless otherwise indicated; $\sim$ Independent Samples T-Test for continuous variables with normal distribution; ^ a nonparametric Mann Whitney U-Test; $\ddagger$ Chi-Squared Test for categorical variables.

Abbreviations: lower in patients with GOLD 3 ( $73 \mathrm{~W}, 47 \%$ predicted) than in patients with GOLD 2 (91 W, 67\% predicted). As expected, peak minute ventilation and ventilatory reserve were significantly lower in patients with GOLD 3 than in patients with GOLD 2. There were no differences in $\mathrm{Vo}_{2}$ peak/weight, peak heart rate, and heart rate reserve $\%$ predicted.

Despite a lower peak work rate in GOLD 3, submaximal exercise response (6 MWD and CWR-70\%) was not significantly different between GOLD 2 and GOLD 3. Muscle function was decreased in both GOLD 2 and GOLD 3 patients. However, QF was only slightly reduced, whereas the decrease of HGF, Pi-max, and Pe-max was clearly more outspoken. In 36 GOLD 2 patients (28\%) and 17 GOLD 3 patients (32\%), QF was less than $80 \%$ pred. No significant differences in muscle function were found between patients with GOLD 2 and patients with GOLD 3. HGF correlated well with QF $(\mathrm{r}=0.72, \mathrm{p}<0.01)$ and FFM $(\mathrm{r}=0.56, \mathrm{p}<0.01)$.

The FFMI was significantly lower in male patients with GOLD 3 compared with male patients with GOLD $2\left(17.0 \mathrm{~kg} / \mathrm{m}^{2}\right.$ versus $\left.17.8 \mathrm{~kg} / \mathrm{m}^{2}, \mathrm{p}<0.05\right)$. In GOLD 2 depletion of FFM and involuntary weight loss was present in $21(17 \%)$ patients. $19(15 \%)$ patients were characterized by a depletion of FFM, $2(2 \%)$ patients reported involuntary weight loss without depletion of FFM and in 1 patient BMI was $\leq 21$ with normal FFM. Differences between smokers and ex-smokers were found in BMI (24.6 (SD 4.2) versus 27.5 (SD 4.3), $\mathrm{p}<0.001$ ), FFMI (16.7 (SD 1.9) versus 17.6 (SD 1.8), $\mathrm{p}<0.01$ ) and fat mass as percentage of total body mass (FM\% weight) (31.6 (SD 6.6) versus 35.4 (SD 6.8), $\mathrm{p}<0.01$ ). $38 \%$ of the smokers had a depletion of FFM versus $10 \%$ of the ex-smokers $(\mathrm{p}<0.001)$.

\section{Parameters associated with exercise capacity in GOLD 2}

In univariate analysis, muscle function parameters $(\mathrm{QF}, \mathrm{QP}-$ $60^{\circ}, \mathrm{QP}-180^{\circ}$, HGF, Pi-max) and DLco were significantly $(\mathrm{p}<0.001)$ related to Wmax and the $6 \mathrm{MWD}$. In contrast, no significant association between $\mathrm{FEV}_{1} \%$ predicted and $\mathrm{Wmax}$ or 6 MWD was found. FFMI was significantly $(\mathrm{p}<0.001)$ related to Wmax, but not to 6 MWD In stepwise multiple regression analysis Wmax was independently associated with height, QF, DLco and age (Table 3). For each $10 \mathrm{Nm}$ decrease in $\mathrm{QF}, \mathrm{Wmax}$ decreased by $2 \mathrm{~W}$ and for each $1 \mathrm{mmol} \cdot \mathrm{min}^{-1}$. $\mathrm{kPa}^{-1}$ decrease in DLco, Wmax decreased by $4 \mathrm{~W}$.

6 MWD was associated with height, age, gender, FFM, DLco, and QF (Table 3). For each $10 \mathrm{Nm}$ decrease in QF, 6 MWD decreased by 4 meter, for each mmol. $\mathrm{min}^{-1} \cdot \mathrm{kPa}^{-1}$ decrease in DLco, 6MWD decreased by 12.3 meter and for 
Table 2 Peak and submaximal exercise response, muscle function, and body composition

\begin{tabular}{|c|c|c|c|c|c|}
\hline & \multicolumn{2}{|l|}{ GOLD 2} & \multicolumn{2}{|c|}{ GOLD 3} & \multirow[b]{2}{*}{$\mathrm{p}$-value } \\
\hline & Mean & SD & Mean & SD & \\
\hline Wmax,W & 91.0 & \pm 30.7 & 74.2 & \pm 26.7 & $\mathrm{p}<0.00 \mathrm{I}$ \\
\hline $\mathrm{Vo}_{2}$ peak, $\mathrm{mL} / \mathrm{min} \sim$ & 1472.8 & \pm 354.4 & 1353.2 & \pm 304 & $\mathrm{p}<0.05$ \\
\hline $\mathrm{Vo}_{2}$ peak/weight, $\mathrm{mL} / \mathrm{kg} / \mathrm{min} \sim$ & 19.2 & \pm 3.9 & 18.1 & \pm 4 & n.s \\
\hline $\mathrm{VcO}_{2}$ peak, $\mathrm{mL} / \mathrm{min} \sim$ & 1535.9 & \pm 407.4 & 1329.8 & \pm 345.6 & $\mathrm{p}<0.05$ \\
\hline $\mathrm{Vco}_{2}$ peak/weight, $\mathrm{mL} / \mathrm{kg} / \mathrm{min} \sim$ & 20 & \pm 4.8 & 17.7 & \pm 4.6 & $\mathrm{p}<0.05$ \\
\hline RQ peak & 1.04 & \pm 0.1 & 0.98 & \pm 0.1 & $\mathrm{p}<0.05$ \\
\hline PAO2 peak mm Hg & 78.2 & \pm 14.5 & 64.1 & \pm 14.4 & $\mathrm{p}<0.00 \mathrm{I}$ \\
\hline $\mathrm{PaACO} 2$ peak $\mathrm{mmHg} \wedge$ & 40.2 & \pm 4.9 & 44.6 & \pm 6.6 & $\mathrm{p}<0.001$ \\
\hline Ve peak, $1 / \min \sim$ & 56.1 & \pm 15.3 & 47 & \pm 12.5 & $\mathrm{p}<0.001$ \\
\hline Ve reserve, \% & I6.1 & \pm 16 & 0 & \pm 20.2 & $\mathrm{p}<0.001$ \\
\hline HR peak, beats/min & 130.6 & \pm 19.6 & 130.7 & \pm 18 & n.s. \\
\hline HR reserve, \% & 14.5 & \pm 11.4 & 15.4 & \pm 10.9 & n.s. \\
\hline $6 \mathrm{MWD}, \mathrm{m} \sim$ & 525.9 & \pm 84.9 & 504.0 & \pm 102.6 & n.s. \\
\hline CWR-70\%, $\min \wedge$ & 14.46 & \pm 12.33 & 11.53 & \pm 8.53 & n.s. \\
\hline Quadr force Nm. & 151.8 & \pm 47.9 & 160.1 & \pm 44.9 & n.s. \\
\hline Quadr force perc. pred & 93.5 & \pm 22.2 & 90.1 & \pm 20 & n.s. \\
\hline Quadr av. power $-60^{\circ}$ (Watt $) \sim$ & 61.8 & \pm 22 & 65.6 & \pm 22 & n.s. \\
\hline Quadr av. power $-180^{\circ}$ (Watt) & 104.4 & \pm 36.5 & 110 & \pm 38.1 & n.s. \\
\hline Handgrip force \% pred & 77.7 & \pm 18.8 & 81.5 & \pm 14.7 & n.s. \\
\hline Pi-max \% pred & 67,1 & \pm 22.5 & 63.4 & \pm 17.8 & n.s. \\
\hline Pe-max \% pred & 51.6 & \pm 18.9 & 48.8 & \pm 15.7 & n.s. \\
\hline BMI $\left(\mathrm{kg} / \mathrm{m}^{2}\right) \sim$ & 27 & \pm 4.4 & 25.9 & \pm 4.4 & n.s. \\
\hline FFMI male $\left(\mathrm{kg} / \mathrm{m}^{2}\right) \sim$ & 17.8 & \pm 1.7 & 17 & \pm 1.5 & 0.01 \\
\hline FFMI female $\left(\mathrm{kg} / \mathrm{m}^{2}\right) \sim$ & 16.9 & \pm 2.2 & 16.3 & \pm 2.2 & n.s. \\
\hline Depletion FFM, n, (\%)‡ & $19(15 \%)$ & & II (2I\%) & & n.s. \\
\hline Nutritional depletion, $\mathrm{n}(\%) \ddagger$ & $20(16 \%)$ & & $12(23 \%)$ & & n.s. \\
\hline FM \% weight male & 32 & \pm 5 & 32 & \pm 6 & n.s. \\
\hline FM \% weight female & 41 & \pm 6 & 44 & \pm 5 & n.s. \\
\hline Invol.Weight loss n & $2(2 \%)$ & & 0 & & \\
\hline
\end{tabular}

Notes: Data are presented as mean \pm SD unless otherwise indicated. Independent Samples T-Test for continuous variables with normal distribution;^ a nonparametric Mann Whitney U-Test; $\neq$ Chi-Squared Test for categorical variables.

Abbreviations:

each $\mathrm{kg}$ increase in FFM, 6 MWD decreased with 5.1 meter (Table 3).

\section{Parameters associated with health- related QoL in GOLD 2}

In univariate analyses QP-60 $(\mathrm{p}<0.05)$, QP-180 $(\mathrm{p}<$ 0.05), HGF ( $p<0.01)$, Pi-max ( $<<0.05), 6$ MWD ( $<<$ $0.001)$, Wmax $(p<0.01)$, and DLco $(p<0.01)$ were significantly associated with SGRQ total score.

In a stepwise multiple regression analysis, the $6 \mathrm{MWD}$ and age were identified as independent determinants of health-related QoL. For each $10 \mathrm{~m}$ decrease in $6 \mathrm{MWD}$,
SGRQ total score worsened by 0.43 units. The activity subscore from the SGRQ was associated with $6 \mathrm{MWD}$, HGF, and age. For each 10 meter decrease in $6 \mathrm{MWD}$, the activity score worsened by 1 unit and for each 10 pounds decrease in HGF the activity score worsened with 1.9 units (Table 3).

\section{Parameters associated with hospitalization in GOLD 2}

Patients with COPD-related hospital admissions during a timeframe of 12 months before the start of the INTERCOM trial were characterized by a significantly $(\mathrm{p}<0.05)$ lower Wmax, QF, HGF, Pi-max than GOLD 2 patients with no 
Table 3 Multivariate linear regression analyses with Wmax, 6 MWD, SGRQ total score, and SGRQ activity subscore as dependant variable in GOLD 2

\begin{tabular}{|c|c|c|c|c|c|c|c|c|}
\hline \multirow[t]{2}{*}{ Dependant variable } & \multicolumn{2}{|l|}{ Wmax* } & \multicolumn{2}{|l|}{ 6MWD** } & \multicolumn{2}{|c|}{ SGRQ total score ${ }^{* * * *}$} & \multicolumn{2}{|c|}{ SGRQ activity***** } \\
\hline & Coefficient (SE) & $\mathrm{p}$-value & Coefficient (SE) & $\mathrm{p}$-value & Coefficient (SE) & $\mathrm{p}$-value & Coefficient (SE) & $\mathrm{p}$-value \\
\hline Constant & -107 & 0.017 & $299(166)$ & 0.075 & $120(25)$ & $<0.001$ & $143(19)$ & $<0.001$ \\
\hline Height (m) & III (28) & $<0.001$ & $349(102)$ & 0.001 & $-36(16)$ & $<0.032$ & & \\
\hline QF (Nm) & $0.2(0.05)$ & $<0.001$ & $0.4(0.19)$ & 0.037 & & & & \\
\hline DLco $\left(\mathrm{mmol} \mathrm{min}^{-1} \cdot \mathrm{kPa}^{-1}\right)$ & $4(1.3)$ & 0.003 & $12.3(4.2)$ & 0.004 & & & & \\
\hline Age (yr) & $-0.7(0.2)$ & 0.004 & $-3.4(0.7)$ & $<0.001$ & & & $-0.39(0.18)$ & $<0.05$ \\
\hline $\mathrm{FFM}(\mathrm{Kg})$ & & & $-5.1(1.2)$ & $<0.001$ & & & & \\
\hline gender & & & $49.8(18)$ & 0.007 & & & & \\
\hline 6MWD (m) & & & & & $-0.043(0.018)$ & $<0.017$ & $-0.1(0.02)$ & $<0.001$ \\
\hline HGF (pounds) & & & & & & & $-0.19(0.07)$ & $<0.01$ \\
\hline F-statistic & 60.7 & & 17.8 & & 9.9 & & 14.8 & \\
\hline adjusted $\mathrm{R}^{2}$ & 0.57 & & 0.48 & & 0.14 & & 0.28 & \\
\hline
\end{tabular}

Notes: *Variables removed from the model FEV, Pi max, HGF, FFM, gender and depletion of FFM; ** Variables removed from the model FEV, Pi max, HGF, and depletion of FFM; *** Variables removed from the model height, gender, QF, DLco, FEV, , Pi max, HGF, Wmax and depletion of FFM; **** Variables removed from the model height, gender, $\mathrm{QF}, \mathrm{DLco}, \mathrm{FEV}$, Pi max, Wmax and depletion of FFM.

Abbreviations:

hospital admissions. In contrast, no significant differences in $\mathrm{FEV}_{1} \%$ predicted were found between patients with and without hospital admissions. In a logistic regression analysis, HGF was an independent determinant of hospitalization (Table 4). For each pound increase in HGF, the odds for a COPD-related hospitalization decreased with 0.96 .

\section{Parameters associated with exacerbations in GOLD 2}

GOLD 2 patients with exacerbations during a timeframe of 12 months prior to the start of the study had a significantly ( $\mathrm{p}<0.05$ ) lower DLco, Wmax, QP-60 ${ }^{\circ}, \mathrm{QP}-180^{\circ}$ compared with GOLD 2 patients who had no exacerbations, while the $\mathrm{FEV}_{1} \%$ predicted was not significantly different between these groups. However, in a logistic regression analysis $\mathrm{FEV}_{1}$ was an independent determinant of exacerbations (Table 4). For each $100 \mathrm{ml}$. increase in $\mathrm{FEV}_{1}$ the odds for a COPDrelated hospitalization decreased with 0.90 .

\section{Discussion}

This study contributes the following novel findings to our knowledge about systemic manifestations of COPD. GOLD 2 patients with an impaired exercise performance are characterized by 1) impaired respiratory muscle function and reduced hand grip force but modestly decreased quadriceps strength 2) below normal fat free mass, particularly in smokers, but low prevalence of recent involuntary weight loss. In these patients with moderate disease, limb muscle function and not airway obstruction was independently associated with exercise capacity, and exercise capacity in turn was independently associated with health-related QoL. Remarkably, hand grip strength as field marker of skeletal muscle strength was identified as predictor of COPD-related hospital admissions. These findings strengthen our hypothesis that these patients may benefit from an interdisciplinary lifestyle program targeted at improving exercise capacity and muscle function, education and promoting self-management skills but also providing

Table 4 Logistic regression analyses with COPD associated hospitalization and exacerbation as dependant variable in GOLD 2

\begin{tabular}{|c|c|c|c|c|c|c|}
\hline \multirow[t]{2}{*}{ Dependant variable } & \multicolumn{3}{|c|}{ COPD-related hospitalization* } & \multicolumn{3}{|l|}{ Exacerbation** } \\
\hline & Coefficient (SE) & p-value & $\operatorname{Exp}(B)$ & Coefficient (SE) & p-value & $\operatorname{Exp}(B)$ \\
\hline Constant & $1.6(0.94)$ & 0.869 & 1.168 & $1.624(0.872)$ & 0.063 & 5.072 \\
\hline HGF (pounds) & $-0.038(0.17)$ & 0.023 & 0.963 & & & \\
\hline $\mathrm{FEV}_{1}$ (decilitre) & & & & $-0.103(0.048)$ & 0.03 & 0.902 \\
\hline
\end{tabular}

Notes: *Variables removed from the model Wmax, 6 MWD, height, gender, QF, HGF, DLco, Pi-max, HGF, FFM, and “depletion of FFM"; ** Variables removed from the model Wmax, 6 MWD, height, gender, QF, DLco, FEV , Pi-max, HGF, FFM, and depletion of FFM.

Abbreviations: 
nutritional counseling, smoking cessation counseling and psychosocial counseling upon indication.

The cause of gradual but progressive deterioration of skeletal muscle function in COPD is largely unknown. Besides progressive inactivity, recent studies suggest that systemic inflammation, measured by highly sensitive C-reactive protein (CRP), may trigger exercise impairment (Palange et al 1995; Creutzberg et al 2004; Steuten et al 2006; Pinto-Plata et al 2006; Torres et al 2006). Unfortunately we were not able to measure CRP in this study population. The cause of systemic inflammation in COPD is also unclear. Studies in COPD and in other chronic diseases such as cardiovascular disease and diabetes indicate that both lungs and extra pulmonary tissues could contribute. A common risk factor of these diseases is smoking (Baarends et al 1997; Engelen et al 2000). Interestingly, we clearly showed in the group of GOLD 2 COPD patients that smokers were characterized by a significantly lower BMI and FFMI compared with exsmokers, which may imply an independent effect of smoking on the muscle cell.

As expected, exercise testing showed significant differences in the peak performance between GOLD 2 and GOLD 3 patients due to a more limited ventilatory capacity. More interestingly, no differences in constant workload cycle ergometry and 6 MWD was seen between GOLD 2 and GOLD 3 patients. This confirms that constant workload test is a better measure to assess and compare exercise capacity for targeting and evaluating rehabilitation and lifestyle interventions and probably also to characterize impairment in daily life activities.

Our study showed that, also in moderate COPD patients, the level of airflow obstruction was not a significant determinant of health-related QoL in contrast to systemic markers of disease severity. Our findings confirm that a relatively simple 6 MWD (Broekhuizen et al 2006) may be sensitive enough to diagnose exercise impairment and the resulting reduction in QoL in early stages of COPD without requiring exhausting and expensive cycle ergometry.

To our knowledge there are no prior studies that have comprehensively investigated exercise impairment in relation to disease burden in mild to moderate COPD. The limited data available support our results. Hamilton reported that in 785 patients with mild to moderate obstructive and nonobstructive pulmonary disease $\left(\mathrm{FEV}_{1} 65 \pm 15 \%\right.$ of predicted $)$ and 919 healthy subjects of similar age, average strength score was $81 \%$ of the reference group and contributed significantly to exercise impairment (Hamilton et al 1995). Clark and colleagues (2000) found in patients with a mean $\mathrm{FEV}_{1}$ of $77 \pm 23 \%$ a reduced isokinetic muscle function compared with healthy sedentary subjects. Coronell (2004) reported that peripheral muscle endurance was impaired in COPD patients even in those with relative normal physical activity and mild to moderate airflow obstruction. This impairment was associated with an early onset of muscle fatigue and could not be predicted from the severity of the disease.

A potential limitation of the present study is a lack of appropriate reference values for the various tests. To allow better interpretation and comparison with other studies, we therefore compared the GOLD 2 patients with the GOLD 3 patients that were also enrolled into the INTERCOM trial. While providing strong evidence for a lifestyle intervention in this cohort, we recognize that our selection criteria limit the external validity of the results to the entire group of GOLD 2 patients (as was also not intended). The small number of hospitalized patients have to be taken into account when considering both the internal and external validity of the study. The observation in this study nevertheless may have important consequences for diagnosis and intervention in patients with GOLD 2 COPD. Assessment of 6 MWD (or an adapted walking test), HGF, and body composition (bioelectrical impedance analysis) are simple field tests and could be integrated in routine assessment of patients with less severe COPD. The outcome of the INTERCOM trial that compares a comprehensive communitybased lifestyle program with usual COPD care, as well as other future studies, will inform us about the potential and cost-effectiveness of early implementation of interdisciplinary lifestyle interventions in less severe stages of COPD.

\section{Acknowledgments}

The authors acknowledge Karin van Mierlo and Esther Phoelich, coordinator nurses of the INTERCOM trial for their outstanding work supervising the logistics of the study and all the technical staff of the lung function laboratory for performing their skilful testing. We also thank Frank Smeenk and Walter van Litsenburg from the Department of Respiratory Medicine, Catharina Ziekenhuis (Eindhoven, The Netherlands) for their participation in the trial and contribution to complete patient recruitment. The authors declare that no financial or other potential conflicts of interest exist. Funding source: Netherlands Asthma Foundation 3.4.01.63 Stichting Astma Bestrijding.

\section{References}

Baarends EM, Schols AM, Mostert R, et al. 1997. Peak exercise response in relation to tissue depletion in patients with chronic obstructive pulmonary disease. Eur Respir J, 10:1856-61.

Bestall JC, Paul EA, Garrod R, et al. 1999. Usefulness of the Medical Research Council (MRC) dyspnoea scale as a measure of disability in patients with chronic obstructive pulmonary disease. Thorax, 54:581-6. 
Black LF, Hyatt RE. 1969. Maximal respiratory pressures: normal values and relationship to age and sex. Am Rev Respir Dis, 99:696-702.

Bourbeau J, Julien M, Maltais F, et al. 2003. Reduction in hospital utilization in patients with chronic obstructive pulmonary disease. Arch Intern Med, 163:585-91.

Broekhuizen R, Wouters E, Creutzberg E, et al. 2006. Elevated CRP levels mark metabolic and functional impairment in advanced COPD. Thorax, 61:17-22.

Clark CJ. Cochrane LM, Mackay E, et al. 2000. Skeletal muscle strength and endurance in patients with mild COPD and the effects of weight. Eur Respir J, 15:92-7. Erratum, Eur Respir J, 2000; 15:816.

Corronell C, Orozco-Levi M, Méndez R, et al. 2004. Relevance of assessing quadriceps endurance in patients with COPD. Eur Respir $J$, 24:129-36.

Creutzberg E, Postma S, Hop J, et al. 2004. Systemic inflammatory response during one year follow-up in patients with COPD. Eur Respir $J$, 24:(Suppl 48)13s.

Decramer M, Gosselink R, Troosters T, et al. 1997. Muscle weakness is related to utilization of health care resources in COPD patients. Eur Respir J, 10:417-23.

Engelen MP, Schols AM, Does JD, et al. 2000. Skeletal muscle weakness is associated with wasting of extremity fat-free mass but not with airflow obstruction in patients with chronic obstructive pulmonary disease Am J Clin Nutr, 71:733-8.

Fletcher CM, Elmes PC, Wood CH. 1959. The significance of respiratory symptoms and the diagnosis of chronic bronchitis in a working population. Br Med J, 1:257-66.

Gosselink R, Troosters T, Decramer M. 1996. Peripheral muscle weakness contributes to exercise limitation in COPD. Am J Respir Crit Care Med, 153:976-80.

Gray-Donald K, Gibbons L, Shapiro SH, et al. 1996. Nutritional status and mortality in chronic obstructive pulmonary disease. Am J Respir Crit Care Med, 153:961-6.

Griffiths TL, Phillips CJ, Davies S, et al. 2001. Cost effectiveness of an outpatient multidisciplinary pulmonary rehabilitation programme. Thorax, 56:779-84.

Hamilton AL, Killian KJ, Summers E, et al. 1995. Muscle strength, symptom intensity and exercise capacity in patients with cardiorespiratory disorders. Am J Respir Crit Care Med, 152:2021-31.

Hoogendoorn M, Feenstra TL, Schermer TR, et al. 2006. Severity distribution of chronic obstructive pulmonary disease (COPD) in Dutch general practice. Respir Med, 100:83-6.
Hurd S. 2000. The impact of COPD on lung health worldwide: epidemiology and incidence. Chest, 117:1S-4S.

Jones NL, Makrides L, Hitchcock C, et al. 1985. Normal standards for an incremental progressive cycle ergometer test. Am Rev Respir Dis, 131:700-8.

Jones PW, Quirk FH, Baveystock CM, et al. 1992. A self-complete measure of health status for chronic airflow limitation. The St. George's Respiratory Questionnaire. Am Rev Respir Dis, 145:1321-7.

Landbo C, Prescott E, Lange P, et al. 1999. Prognostic value of nutritional status in chronic obstructive pulmonary disease. Am J Respir Crit Care Med, 160:1856-61.

Landis J, Koch G. 1977. The measurement of observer agreement for categorical data. Biometrics, 33:159-74.

Murray CJL, Lopez AD. 1997. Mortality by cause for eight regions of the world: Global Burden of Disease Study. Lancet, 349:1269-76.

Nici L, Donner C, Wouters E, et al. 2006. American Thoracic Society/ European Respiratory Society statement on pulmonary rehabilitation. Am J Respir Crit Care Med, 173:1390-413.

Palange P, Forte S, Felli A, et al. 1995. Nutritional state and exercise tolerance in patients with COPD. Chest, 107:1206-12.

Pinto-Plata VM, Mullerova H, Toso JF, et al. 2006. C-reactive protein in patients with COPD, control smokers and non-smokers. Thorax, 61:23-8.

Quanjer PH. 1993. Standardized lung function testing. Official statement of the European Respiratory Society. Eur Respir J, 6(suppl 16):1-100.

Schols AM, Broekhuizen R, Weling-Scheepers CA, et al. 2005. Body composition and mortality in chronic obstructive pulmonary disease. Am J Clin Nutr, 82:53-9.

Schols AMWJ, Wouters EFM, Soeters PB, et al. 1991. Body composition by bioelectrical-impedance analysis compared with deuterium dilution and skinfold anthropometry in patients with chronic obstructive pulmonary disease. Am J Clin Nutr, 53:421-4.

Steuten LM, Creutzberg EC, Vrijhoef HJ, et al. 2006. COPD as a multicomponent disease: inventory of dyspnoea, underweight, obesity and fat free mass depletion in primary care. Prim Care Respir J, 15:84-91.

Torres JP, Cordoba-Lanus E, López-Aguilar C, et al. 2006. C-reactive protein levels and clinically important predictive outcomes in stable COPD patients. Eur Respir J, 27:902-7.

Wouters EF. 2002. Chronic obstructive pulmonary disease: systemic effects of COPD. Thorax, 57:1067-70. 
